\title{
Finite Element Modeling of Variable Membrane Thickness for Field Fabricated Spherical (LNG) Pressure Vessels
}

\author{
Oludele Adeyefa, Oluleke Oluwole \\ Department of Mechanical Engineering, University of Ibadan, Ibadan, Nigeria \\ Email: oluwoleo2@asme.org
}

Received January 29, 2013; revised March 2, 2013; accepted March 9, 2013

Copyright (C) 2013 Oludele Adeyefa, Oluleke Oluwole. This is an open access article distributed under the Creative Commons Attribution License, which permits unrestricted use, distribution, and reproduction in any medium, provided the original work is properly cited.

\begin{abstract}
This study investigated thickness requirements for field fabricated (large) spherical liquefied natural gas (LNG) pressure vessels using the finite element method. In the FEM modeling, 3-dimenisonal analysis was used to determine thickness requirements at different sections of a 5-m radius spherical vessels based on the allowable stress of the material as given in ASME Section II Part D. Shallow triangular element based on shallow shell formation was employed using area coordinate system which had been proved better than the global coordinate system in an earlier work of the authors applied to shop built vessels. This element has five degrees of freedom at each corner node-five of which are the essential external degrees of freedom excluding nodal degree of freedom associated with in plane shell rotation. Set of equations resulting from Finite Element Analysis were solved with computer programme code written in FORTRAN 90 while the thickness requirements of each section of spherical pressure vessels subjected to different loading conditions were determined. The results showed membrane thickness decreasing from the base upwards for LNG vessels but constant thickness for compressed gas vessels. The obtained results were validated using values obtained from ASME Section VIII Part UG. The results showed no significant difference $(P>0.05)$ with values obtained through ASME Section VIII Part UG.
\end{abstract}

Keywords: LNG; FEM; Field Fabricated Pressure Vessels; Shell Thickness; Modeling

\section{Introduction}

Over the past few decades, world consumption of LNG has increased more than five-fold and it is predicted that this growth will continue to be very strong. The growing demand from large markets such as China and India combined with the increasing popularity in a large number of other smaller markets has resulted in the development of many new LNG facilities throughout the world. There are significant natural gas reserves globally and exploration companies are rapidly developing facilities for exporting the natural gas with corresponding receiving facilities being planned and built in emerging markets. With a timeframe of some 5 - 10 years required for planning and construction, there is currently much activity underway in the LNG supply chain in preparation for current and predicted demands. Because of its unexampled advantages such as less floor area covering, highpressure capability and transport facilitates, Spherical pressure vessels used for storage of gas and liquefied gas more widely than other storage tanks in the oil, gas, chemical and other fields.

Since the 1990s, the number of nuclear fuel storage and LNG storage facilities have increased, interest in the safety of these facilities have also increased as well as researches related to these fields $[1,2]$. Single-curvature polyhedron hydro-bulging technology is a new technology for manufacturing spherical vessels and it has a good application foreground. This technology has been used in practice, but the designing and manufacturing of polyhedral are based on experiences, and the final quality of spherical vessels cannot be forecast quantitatively. Dong and other workers [3] in their paper, used the FEM code, MARC to simulate the hydro-bulging process of a singlecurvature polyhedron, including loading and offloading. The distributions of stress and strain were simulated as well as other important data in their work [3]. Comparing with experimental data, their work showed that singlecurvature polyhedron hydro-bulging process could be simulated well by the finite element method code. The authors [4-6] have worked on shop built spherical vessels 
design and stress modeling in spherical vessels using global and area coordinate systems in the finite element modeling. Different design specifications and selection procedures have been outlined [7,8]. Construction of shop built spherical [9] and field fabricated cylindrical vessels have being carried out [10], however, there is still intense interest in the designing of spherical pressure vessels [11-13]. Work has proved the area coordinate system for triangular shell elements reliable and easy to use than the global coordinate system [5,6]. Thus the area coordinates system was applied in this modeling.

\section{Methodology}

\subsection{Finite Element Modeling}

Finite element analysis was used in this work. The analysis of this system required transformation into a discrete mathematical system [14]. The simplified structural model consisted of discrete structural elements (4 elements) as opposed to the system used in an earlier method $[4,5]$ which needed fine meshing to converge to a stress level. The approximate behavior of each element was expressed in terms of selected generalized stress and strain variables using elasticity theory. The elements were then assembled by enforcing equilibrium of forces and compatibility of displacements at the nodes on the model. These conditions were expressed as a set of nonhomogenous linear equations in which the variables were element forces and structural displacements and the constant terms were the applied loads [14].

\subsection{Displacement Functions}

The use of shallow triangular element (Figure 1) and "area coordinates" was made use of in this work to represent the transverse displacement, $\mathrm{w}$, as a polynomial function of degree 3 as given by [15]. Linear polynomial equations were then used to represent the membrane displacements $\mathrm{u}$ and $\mathrm{v}$ using area coordinates, resulting in a constant strain triangle for the membrane action. The assumed displacement equations are:

$$
\begin{aligned}
& u=a_{1} L_{1}+a_{2} L_{2}+a_{3} L_{3} \\
& v=a_{4} L_{1}+a_{5} L_{2}+a_{6} L_{3}
\end{aligned}
$$

$$
\begin{aligned}
w= & a_{7} L_{1}+a_{8} L_{2}+a_{9} L_{3}+a_{10} L_{1} L_{2}+a_{11} L_{2} L_{3}+a_{12} L_{3} L_{1} \\
& +a_{13}\left[L_{1}^{2} L_{2}+\frac{1}{2} L_{1} L_{2} L_{3}\left\{3\left(1-\mu_{3}\right) L_{1}-\left(1-3 \mu_{3}\right) L_{2}+\left(1-3 \mu_{3}\right) L_{3}\right\}\right] \\
& +a_{14}\left[L_{1}^{2} L_{2}+\frac{1}{2} L_{1} L_{2} L_{3}\left\{3\left(1-\mu_{3}\right) L_{1}-\left(1-3 \mu_{3}\right) L_{2}+\left(1-3 \mu_{3}\right) L_{3}\right\}\right] \\
& +a_{15}\left[L_{1}^{2} L_{2}+\frac{1}{2} L_{1} L_{2} L_{3}\left\{3\left(1-\mu_{3}\right) L_{1}-\left(1-3 \mu_{3}\right) L_{2}+\left(1-3 \mu_{3}\right) L_{3}\right\}\right]
\end{aligned}
$$

$$
\begin{gathered}
\theta_{x}=\frac{\partial w}{\partial y} \\
\theta_{y}=-\frac{\partial w}{\partial x}
\end{gathered}
$$

where

$$
\mu_{i}=\frac{l_{k}^{2}-l_{j}^{2}}{l_{i}^{2}}
$$

and $l_{i}$ is the length of the side opposite node $i$. The modified interpolation for displacement is taken as

$$
\phi=P a
$$

to determine constants $a_{s}$, known displacements at nodes are substituted and the equations become

$$
[\boldsymbol{a}]=\left[C^{-1}\right][\delta]
$$

where $[\delta]$ is the nodal degrees of freedom, $\left[C^{-1}\right]$ is inverse of transformation matrix and $[\boldsymbol{a}]$ is vector of in- dependent constants.

\subsection{Strain-Displacement Equations}

Strain-displacement relationships for shallow thin shells as given by [16] are simplified for the shallow shell and expressed as follows in curvilinear coordinates.

$$
\begin{aligned}
& \varepsilon_{x}=\frac{\partial u}{\partial x}+\frac{w}{r}, \varepsilon_{y}=\frac{\partial v}{\partial y}+\frac{w}{r}, k_{x}=-\frac{\partial^{2} w}{\partial x^{2}} \\
& k_{y}=-\frac{\partial^{2} w}{\partial y^{2}}, k_{x y}=-2 \frac{\partial^{2} w}{\partial x \partial y}
\end{aligned}
$$

The above strain Equation (8) can be written in matrix form after necessary substitutions of $u, v$ and $w$ in Equations (1)-(3) into the above strain equations.

\subsection{Stresses in a Curved Triangular Element}

Stress varies from point to point along the shell profile and also through the thickness of the shell making it an 


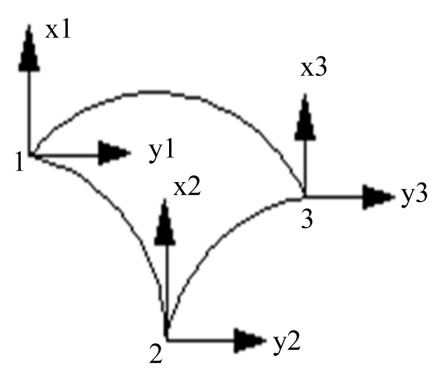

Figure 1. Shallow triangular element.

unknown function of two variables [14]. It is represented as shown below [4]:

$$
\sigma_{b}=\frac{6 M}{t^{2}}, \sigma_{m}=\frac{N}{t}
$$

where: $M$ is the moment per unit length, $M$ and $\sigma_{b}$ is the bending stress at the surface.

$N$ is force per unit length and $\sigma_{m}$ which is membrane stress.

\subsection{Strain Energy}

The strain energy equation for an isotropic linear shell as given by [17] was adopted in this work;

$$
\begin{aligned}
U= & \iint_{A} \int_{-\frac{t}{2}}^{\frac{t}{2}} \frac{E}{2\left(1-v^{2}\right)} \\
& \cdot\left[\varepsilon_{x}^{2}+\varepsilon_{y}^{2}+2 v \varepsilon_{x} \varepsilon_{y}+\frac{1}{2}(1-v) \gamma_{x y}^{2}\right] \mathrm{d} \varsigma \mathrm{d} x \mathrm{~d} y
\end{aligned}
$$

where, $t=$ thickness of the shell, $v=$ Poisson's ratio and $E=$ Modulus of elasticity $\varepsilon$ and $\gamma$ are the strain and shear strain notations.

After substitution for strains in the above expression and integration with respect to $\varsigma$, the strain energy can be separated into the membrane energy $U_{m}$ and the bending energy $U_{b}$.

$$
\begin{gathered}
U=U_{m}+U_{b} \\
U_{m}=\frac{E t}{2\left(1-v^{2}\right)} \iiint_{A}\left[e_{x}^{2}+e_{y}^{2}+2 v e_{x} e_{y}+\frac{1}{2}(1-v) e_{x y}^{2}\right] \mathrm{d} x \mathrm{~d} y \\
U_{b}=\frac{E t^{3}}{24\left(1-v^{2}\right)} \iiint_{A}\left[k_{x}^{2}+k_{y}^{2}+2 v k_{x} k_{y}+\frac{1}{2}(1-v) k_{x y}^{2}\right] \mathrm{d} x \mathrm{~d} y
\end{gathered}
$$

The potential energy, $\Phi=U-W$ where $W$ represents the work done by the external load on the system. In the finite element method, the potential energy of a shell is expressed as:

$$
\Phi=\sum_{k=1}^{n} \phi_{k}
$$

where $\phi_{k}$ is the potential energy of the $k^{\text {th }}$ element.

\subsection{Stiffness Matrix}

$$
\begin{gathered}
k_{m}=t\left[C^{-1}\right]^{\mathrm{T}} \iint_{A} B_{m}^{\mathrm{T}} D_{m} B \mathrm{~d} A\left[C^{-1}\right] \\
k_{b}=t\left[C^{-1}\right]^{\mathrm{T}} \iint_{A} B_{b}^{\mathrm{T}} D_{b} B \mathrm{~d} A\left[C^{-1}\right]
\end{gathered}
$$

$k_{m}$ and $k_{b}$ are element stiffness matrices due to membrane and bending stresses respectively $D_{m}$ and $D_{b}$ are elasticity matrices for membrane and bending stresses respectively $B_{m}$ and $B_{b}$ are strain matrices for membrane and bending stresses respectively.

Therefore, element total stiffness matrix is

$$
k=k_{b}+k_{m}
$$

The element stiffness matrices were then combined to give the system stiffness matrix. The stiffness matrices $k_{b}$ and $k_{m}$ in terms of area coordinates were using three Gauss quadrature points. To integrate explicitly, the integral equation below as it is in [6] was very useful.

$$
\int_{A} L_{1}^{a} L_{2}^{b} L_{3}^{c} \mathrm{~d} A=\frac{a ! b ! c !}{(a+b+c+2) !} 2 \Delta
$$

where $\Delta$ is the area of triangular element

\subsection{Consistent Load Vector}

It is well known fact that the best and accurate approach for dealing with distributed loads in FEM is the use of a consistent load vector which is derived by equating the work done by the distributed load through the displacement of the element to the work done by the nodal generalized loads through the nodal displacements. The shallow triangular shell element acted upon by a distributed load q per unit area in the direction of w, has work done by this load given by:

$$
P_{1}=\int_{A} q w \mathrm{~d} x \mathrm{~d} y
$$

where $w$ is:

$$
\{w\}=[P]\{a\}=[P]\left[C^{-1}\right]\{\delta\}
$$

and $[P]$ for the present element is given as

$$
\begin{aligned}
& P \\
& =\left[\begin{array}{lllllllllllllll}
0 & 0 & 0 & 0 & 0 & 0 & L_{1} & L_{2} & L_{3} & L_{1} L_{2} & L_{2} L_{3} & L_{3} L_{1} & P_{13} & P_{14} & P_{15}
\end{array}\right]
\end{aligned}
$$


where

$$
\begin{aligned}
& P_{13}=\left[L_{1}^{2} L_{2}+\frac{1}{2} L_{1} L_{2} L_{3}\left\{3\left(1-\mu_{3}\right) L_{1}-\left(1-3 \mu_{3}\right) L_{2}+\left(1-3 \mu_{3}\right) L_{3}\right\}\right] \\
& P_{14}=\left[L_{1}^{2} L_{2}+\frac{1}{2} L_{1} L_{2} L_{3}\left\{3\left(1-\mu_{3}\right) L_{1}-\left(1-3 \mu_{3}\right) L_{2}+\left(1-3 \mu_{3}\right) L_{3}\right\}\right] \\
& P_{15}=\left[L_{1}^{2} L_{2}+\frac{1}{2} L_{1} L_{2} L_{3}\left\{3\left(1-\mu_{3}\right) L_{1}-\left(1-3 \mu_{3}\right) L_{2}+\left(1-3 \mu_{3}\right) L_{3}\right\}\right]
\end{aligned}
$$

and $\mu$ is as defined in Section 2.2.

The work done by the consistent nodal generalized force through the nodal displacements $\{\delta\}$ is given by:

$$
P_{2}=\left\{F^{\mathrm{T}}\right\}\{\delta\}
$$

Hence, from Equations (19)-(22), the nodal forces were obtained

$$
F=\left[C^{-1}\right]^{\mathrm{T}} \int\left[P^{\mathrm{T}}\right] q \mathrm{~d} x \mathrm{~d} y
$$

Equation (23) gives the nodal forces on a single element; and the nodal forces for the whole structure were obtained by assembling the elements' nodal forces.

\subsection{Boundary Conditions}

Before the system equations are ready for solution, they must be modified to account for the boundary conditions of the problem. For this system, it was assumed that displacements in all directions with the exception of radial direction are zero. Also, due to the symmetry nature of the system, 1/6 of the spherical vessel (Figure 2) was used thereby reducing computing time. Shown (Figure 2) is sample of meshing of $1 / 6$ of the spherical vessel with 4 elements and 6 nodes as used in this work.

Figure 3 shows the arrangement for the elements in the spherical shell. Course 1 takes thickness of Element 1 . The lower and upper portions of Course 2 take thicknesses of Elements 2 and 3 respectively while Course 3 has thickness corresponding to the thickness of Element 4.

\subsection{Cases Considered}

\section{Case 1: Storage Tank Storing LNG}

For a spherical vessel with the following simulation parameters, the thickness of each element corresponding to the membrane stress developed at the centroid was determined (Table 1). Membrane stresses at the centroid were deliberately programmed to be within the range of $0.5 \%$ and $0.8 \%$ less than the spherical vessel construction material allowable stress given by ASME standard to avoid a rise over the allowable membrane stress.

Design Internal Pressure $=600 \mathrm{KN} / \mathrm{m}^{2}$

Density of Stored Product $=560 \mathrm{Kg} / \mathrm{m}^{3}$

Material of Construction $=$ A516M Grade 70

Material Allowable Stress $=138 \mathrm{MN} / \mathrm{m}^{2}$

Specified Minimum Yield stress $=260 \mathrm{MPa}$

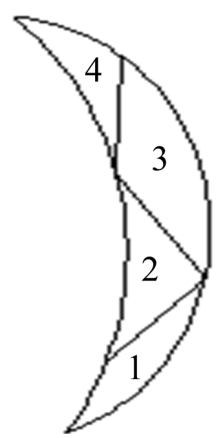

Figure 2. Typical spherical mesh.



Figure 3. 3-course version spherical vessel.

Material Factor of safety $=1.88$

Radius of Spherical Vessel $=5.0$ metres

Case 2: Storage Tank Storing Compressed Gas

Thickness of each element corresponding to the membrane stress developed at the centroid was determined for spherical vessels storing compressed gas (Table 2). Membrane stresses at the centroid were deliberately programmed to be within the range of $0.5 \%$ and $0.8 \%$ less than the spherical vessel construction material allowable stress to avoid a rise over the allowable membrane stress.

Internal Design Pressure $=600 \mathrm{KN} / \mathrm{m}^{2}$

Material of Construction = A516M Grade 70

Material Allowable Stress $=138 \mathrm{MN} / \mathrm{m}^{2}$

Specified Minimum Yield stress $=260 \mathrm{MPa}$

Material Factor of safety $=1.884$

Radius of Spherical Vessel $=5.0$ metres

\section{Results and Discussions}

Tables 1 and $\mathbf{2}$ show the thicknesses and developed stress values obtained for storage vessels storing LNG and compressed gas respectively. These values were explicitly brought out in Figures 4-7. It could be observed that for the storage tank storing LNG that the membrane thickness is thicker at the base decreasing upwards (Figure 4). For the tank storing compressed gas there is uniform thickness throughout the tank (Figure 6). It Could be seen as well that the safety factor given for the stress developed at the centroid of each element has not exceeded the material allowable stress for both tanks (Figures 5 and 7) and hence both tanks are operating at stresses below the 
Table 1. Element thicknesses for spherical vessel storing liquefied product (LNG).

\begin{tabular}{lccccc}
\hline & $t_{\text {FEA }}(\mathrm{m})$ & $t_{\text {ASME }}(\mathrm{m})$ & \% Deviation & Developed Stress (MPa) & Factor of Safety \\
\hline Element 1 & 0.01210 & 0.01178 & 2.64 & 137.5 & 1.89 \\
Element 2 & 0.01160 & 0.01153 & 0.60 & 137.7 & 1.89 \\
Element 3 & 0.01150 & 0.01122 & 2.43 & 137.5 & 1.89 \\
Element 4 & 0.0110 & 0.01097 & 0.27 & 137.5 & 1.89 \\
\hline
\end{tabular}

Table 2. Element thicknesses for spherical vessel storing compressed gas.

\begin{tabular}{llcccc}
\hline & $t_{\text {FEA }}(\mathrm{m})$ & $t_{\text {ASME }}(\mathrm{m})$ & \% Deviation & Developed Stress (MPa) & Factor of Safety \\
\hline Element 1 & 0.01090 & 0.01087 & 0.275 & 137.5 & 1.891 \\
Element 2 & 0.01090 & 0.01087 & 0.275 & 136.3 & 1.908 \\
Element 3 & 0.01090 & 0.01087 & 0.275 & 137.0 & 1.898 \\
Element 4 & 0.01090 & 0.01087 & 0.275 & 137.0 & 1.898 \\
\hline
\end{tabular}

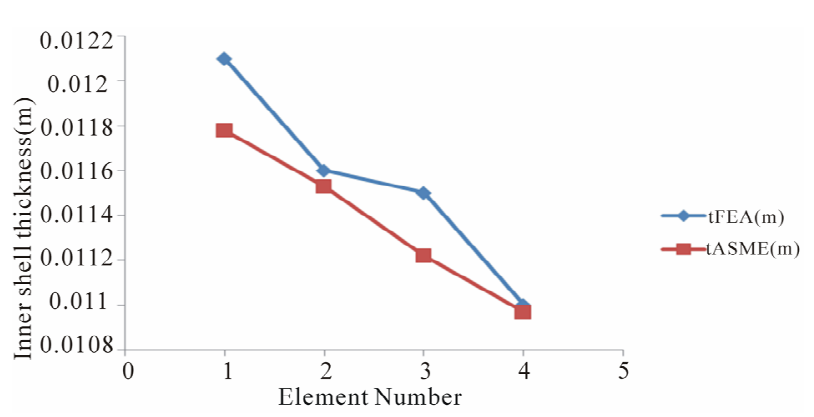

Figure 4. Element thicknesses for spherical vessel storing liquefied product (LNG).



Figure 5. Developed stresses in spherical vessel storing liquefied product (LNG).



Figure 6. Element thicknesses for spherical vessel storing compressed gas.

specified minimum yield stress given by ASME code. It could also be seen from Tables $\mathbf{1}$ and $\mathbf{2}$ that the thicknesses calculated for each element are in close agreement

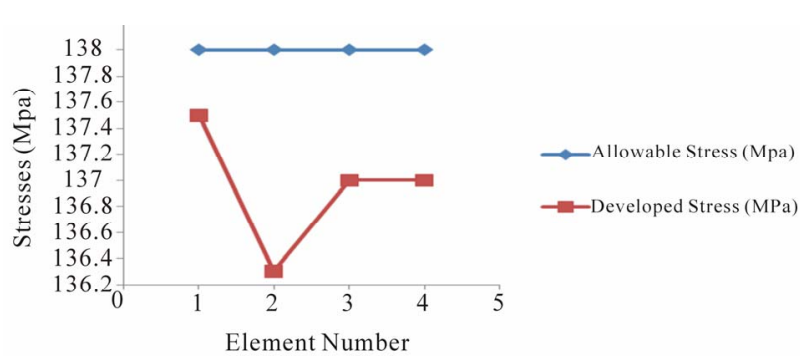

Figure 7. Developed stresses in spherical vessel storing compressed gas.

with ASME values. The maximum percentage deviation from the thicknesses using FE model and ASME is $2.64 \%$. This percentage value is reasonable as the results showed no significant difference $(P>0.05)$. The wisdom in deliberately programming the allowable stress to be within the range of $0.5 \%$ and $0.8 \%$ less than the spherical vessel construction material allowable stress could be seen here because all the stress values fall a little below the allowable membrane stress. The FE model in this research work also proved that it is possible to obtain reasonable results with few elements using area coordinates as opposed to the large number of elements needed for the model developed by Adeyefa et al. [5] using global coordinates. Thus the use of area coordinates allow an easy modelling of variable vessel thickness which would otherwise would have become impossible using global coordinates.

\section{REFERENCES}

[1] H. M. Koh, J. K. Kim and J. H. Park, "Fluid-Structure Interaction Analysis of 3-D Rectangular Tanks by a Variationally Coupled BEM-FEM and Comparison with Test Results," Earthquake Engineering and Structural Dynamics, Vol. 27, No. 2, 1998, pp. 109-124. doi:10.1002/(SICI)1096-9845(199802)27:2<109::AID-E QE714>3.0.CO;2-M 
[2] Y.-S. Choun and C.-B. Yun, "Sloshing Analysis of Rectangular Tanks with a Submerged Structure by Using Small-Amplitude Water Wave Theory," Earthquake Engineering and Structural Dynamics, Vol. 28, No. 7, 1999, pp. 763-783.

doi:10.1002/(SICI)1096-9845(199907)28:7<763::AID-E QE841>3.0.CO;2-W

[3] J. Dong, et al., "Numerical Calculation and Analysis of Single -Curvature Polyhedron Hydro-Bulging Process for Manufacturing Spherical Vessels," Institute of Nuclear Energy Technology, Tsinghua University, Beijing, 2005.

[4] O. A. Adeyefa and O. O. Oluwole, "Finite Element Modeling of Stress Distribution in Spherical Liquefied Natural Gas (LNG) Pressure Vessels," Proceedings of the Nigerian Institute of Industrial Engineers, Nigerian Institute of Industrial Engineers, Abuja, 2011, pp. 65-78.

[5] O. A. Adeyefa and O. O. Oluwole, "Finite Element Analysis of Von-Mises Stress Distribution in a Spherical Shell of Liquified Natural Gas (LNG) Pressure Vessels,” Engineering, Vol. 3, No. 10, 2011, pp. 1012-1017.

[6] O. A. Adeyefa and O. O. Oluwole, "Finite Element Modeling of Shop Built Spherical (LNG) Pressure Vessels,” Engineering, Unpublished, 2013.

[7] AIJ, “Design Recommendation for Storage Tanks,” 2011. www.aij.or.jp/jpn/databox/2011

[8] Kolmetz, "Storage Tanks Selection and Sizing,” 2011.
http://kolmetz.com/pdf/EDG/ENGINEERING_DESIGN GUIDELINE_storage_tank_rev_2.pdf

[9] Wilco, "Spherical Compressed Natural Gas Vessels," 2012. www.wilcofab.com/wilcocompressedn.html

[10] Y.-M. Yang, J.-H. Kim, H.-S. Seo, K. Lee and I.-S. Yoon, "Development of the World's Largest Above-Ground Full Containment LNG Storage Tank," 23rd World Gas Conference, Amsterdam, 5-9 June 2006, pp. 1-14.

[11] EGPET, “LPG Spherical Storage Tank Design,” 2012. www.egpet.net/vb/threads/25114Sphericalstoragetank

[12] Wikipedia, “Storage Tank," 2012. http://en.wikipedia.org/wiki/Storage_tank

[13] Wikipedia, "Pressure Vessel," 2012. http://en.wikipedia.org/wiki/Pressure_vessel

[14] S. I. Mahadeva, "Analysis of a Pressure Vessel Junction by the Finite Element Method,” Ph.D. Dissertation, Texas Tech University, Lubbock, 1972.

[15] O. C. Zienkiewicz and R. L. Taylor, "The Finite Element Method Set,” 5th Edition, Vol. 2: Solid Mechanics, Butterworth-Heinemann, Oxford, 2000.

[16] E. Reissner, "On Some Problems in Shell Theory,” Proceedings of 1st Symposium on Naval Structural Mechanics, California, 11-14 August 1958.

[17] H. L. Langhaar, "Energy Methods in Applied Mechanics,” Wiley \& Sons, New York, 1962. 